\title{
Hubungan Durasi Terdiagnosis Diabetes Melitus Tipe 2 dan Kadar Gula Darah Sewaktu Dengan Kejadian Retinopati Diabetik di Rumah Sakit Budi Kemuliaan Kota Batam Tahun 2017-2018
}

\author{
${ }^{(1)}$ Sukma Sahreni, ${ }^{(2)}$ Isramilda, ${ }^{(3)}$ Andi Ipaljri Saputra \\ Fakultas Kedokteran Universitas Batam ${ }^{(1)(2)(3)}$ \\ sukmasahreni@univbatam.ac.id ${ }^{(1)}$, isramilda@univbatam.ac.id ${ }^{(2)}$,andiipaljri@univbatam.ac.id ${ }^{(3)}$
}

\begin{abstract}
ABSTRAK
Hubungan Durasi Terdiagnosis Diabetes Melitus Tipe 2 Dan Kadar Gula Darah Dengan Kejadian Retinopati Diabetik Di Rumah Sakit Budi Kemuliaan Kota Batam Tahun 2017-2018. Retionopati Diabetik merupakan salah satu komplikasi mikrovaskular Diabetes Melitus yang disebabkan oleh kerusakan pembuluh darah di retina dan dapat menimbulkan kebutaan yang permanen. Retinopati diabetes merupakan respon target organ terhadap penyakit sistemik dan hanya merupakan salah satu dari berbagai komplikasi mikrovaskular dari Diabetes mellitus. Jenis penelitian ini merupakan penelitian analitik observasional dengan pendekatan studi case control, dengan menelaah hubungan antara efek (penyakit atau kondisi kesehatan) tertentu dengan faktor risiko tertentu. Sampel pada penelitian ini berjumlah 66 orang. Teknik pengambilan sampel menggunakan Total sampling. Analisis data menggunakan uji chi-square. Dari hasil penelitian 66 orang yang diteliti sebanyak $38(57,6 \%)$ orang memiliki durasi diabetes mellitus $\leq 5$ tahun. Hasil Uji Risk Estimate menunjukkan nilai Odds Ratio $(\mathrm{OR})=6,500$. OR $>1$ Yang artinya, peluang $\leq 5$ tahun pasien Retinopati Diabetik memiliki resiko diabetes melitus tipe 2 sebesar 6,500 lebih tinggi daripada pasien $>5$ tahun. Hasil Uji Risk Estimate menunjukkan nilai Odds Ratio $(\mathrm{OR})=3,200$. OR $>1$ Yang artinya, Kadar Gula Darah terkontrol dengan tidak terjadi Retinopati Diabetik memiliki resiko sebesar 3,200 lebih tinggi daripada dari pada yang terjadi Retinopati. Berdasarkan hasil penelitian ini dapat di simpulkan bahwa ada hubungan yang signifikan antara Diabates Melitus tipe 2 dan kadar gula darah sewaktu dengan kejadian Retinopati Diabetik di Rumah Sakit Budi Kemuliaan Kota Batam tahun 2017 - 2018.
\end{abstract}

Kata Kunci : Diabetes Mellitus, Gula Darah, Retinopati

\begin{abstract}
The relation of Diabetes Type 2 Diabetes Mellitus And Blood Sugar Levels With Diabetic Retinopathy In Batam City Budi Kemuliaan Hospital Year 2017-2018. Diabetic retinopathy is one of the microvascular complications of Diabetes Melitus caused by damage to blood vessels in the retina and can cause permanent blindness. Diabetic retinopathy is the target organ response to systemic diseases and is only one of the various microvascular complications of Diabetes mellitus. This type of research is an observational analytic study with a case control study approach, by examining the relationship between certain effects (disease or health condition) and certain risk factors. The sample in this study amounted to 66 people. The sampling technique uses total sampling. Data analysis using chi-square test. From the results of the study of 66 people studied 38 $(57.6 \%)$ people had a duration of diabetes mellitus $\leq 5$ years. The Risk Estimate Test results show the value of Odds Ratio $(\mathrm{OR})=6,500$. OR $>1$ Which means, the chance of $\leq 5$ years of patients with Diabetic Retinopathy has a risk of type 2 diabetes mellitus of 6,500 higher than patients $>5$ years. The Risk Estimate Test results show the value of Odds Ratio $(\mathrm{OR})=3,200$. OR $>1$ Which means, controlled blood sugar levels with no occurrence of diabetic retinopathy have a risk of 3,200 higher than that of retinopathy. Based on the results of this study it can be concluded that there is a significant relationship between Type 2 diabetes mellitus and blood sugar levels when with the incidence of Diabetic Retinopathy in Batam City Budi Kemuliaan Hospital 2017 2018
\end{abstract}

Keywords : Diabetes Mellitus, Blood Sugar, Retinopathy 
Sahreni S, Isramilda, Saputra AI : Hubungan Durasi Terdiagnosis Diabetes Melitus Tipe 2 dan Kadar Gula Darah Sewaktu Dengan Kejadian Retinopati Diabetik di Rumah Sakit Budi Kemuliaan Kota Batam Tahun 2017-2018

\section{PENDAHULUAN}

\section{Latar Belakang}

Retinopati Diabetik (RD) merupakan salah satu komplikasi mikrovaskular Diabetes Melitus yang disebabkan oleh kerusakan pembuluh darah di retina dan dapat menimbulkan kebutaan yang permanen (Kementrian Kesehatan RI, 2014). Retinopati diabetes merupakan respon target organ terhadap penyakit sistemik dan hanya merupakan salah satu dari berbagai komplikasi mikrovaskular dari Diabetes mellitus ( Aillo L., Cahill M.M.J. 2001). International Diabetic Federation (IDF 2011) menyatakan prevalensi terbesar Retinopati diabetik berada di wilayah Asia Tenggara sebayak 41\%, di Eropa 20\%, Amerika 19\%,di Pasifik Barat 19\%,di kawasan Mediterania Timur 18\%, dan di Afrika 12\%. Pada tahun 2011 terdapat lebih dari 40 juta orang menderita RD di asia tenggara. (Schmieder RE. 2009). Di Indonesia sendiri dilaporkan, The DiabCare Asia 2008 Study bahwa prevalensi penderita DM mengalami komplikasi retinopati non proliferatif adalah $42 \%$, dan $6,4 \%$ di antaranya merupakan retinopati proliferatif. Di Eropa, berdasarkan penelitian survey populasi di Melton Mowray, England prevalensi retinopati pada pasien dengan pengobatan insulin sebesar $41 \%$ dan pasien tanpa pengobatan insulin sebesar 52\%.14 Data dari western Scotland prevalensi retinopati diabetika sebesar 26,7\% dan retinopati serius (RDNP, RDP, Makula) sekitar 10\%. (Schmieder RE. 2009). RD menjadi penyebab utama kehilangan penglihatan akibat komplikasi Diabetes melitus pada orang dewasa. Kebutaan akibat Retinopati diabetik menjadi masalah kesehatan yang harus di wspadai karena menurunkan produktivitas bagi penderita dan menjadi beban sosial di masyarakat (Sitompul, 2001). Non - proliferative diabetic retinopathy (RDNP) yang merupakan stadium awal dari penyakit, perubahan pembuluh darah retina pada RDNP terbatas pada retina dan tidak meluas melampaui membran limitan interna. Karakteristik pada NPDR mencakup mikroaneurisma, nerve fiber layer infarcts, IRMAs, perdarahan intraretinal dot blot, edema retina, hard exudat, kelainan arteriol, vena retina dilatasi dan vena beading. Proliferative diabetic retinopathy ( PDR) merupakan bentuk yang lebih berat. Proliferative fibrovaskular eksraretinal bervariasi pada retinopati diabetik proliferative. Lokasi neovascular proliferation dijumpai pada daerah disc dan di tempat lainnya (AAO, 2010;David J 2005). Peningkatan kadar glukosa darah sewaktu $\geq 200 \mathrm{mg} / \mathrm{dL}$ yang disertai dengan gejala poliuria, polidipsia, polifagia, dan penurunan berat badanyang tidak dapat dijelaskan sebabnya sudah cukup untuk menegakkan diagnosis DM (Soegondo S, Soewondo P, Subekti I.). Patofisiologi terjadinya retinopati diabetikum selalu mengalami perkembangan terbaru sejalan dengan penelitian-penelitian yang dilakukan. Kondisi hiperglikemi yang berlangsung secara kronik dapat menginisiasi kaskade perubahan biokimia dan fisiologi yang akhirnya mengakibatkan kerusakan pada mikrovaskular dan retina (Cheung et al, 2010). Diabetes melitus tipe 2 merupakan tipe diabetes yang paling banyak ditemukan dengan proporsi $90 \%$ dari seluruh kasus DM. Dengan besarnya proporsi tersebut, kelompok ini berisiko paling tinggi terhadap sejumlah komplikasi DM (Kementrian Kesehatan RI, 2014). American Diabetes Association (2010) menyebutkan bahwa banyaknya penderita DM tipe 2 meningkatkan beban penyakit akibat retinopati diabetik. Menurut Jones et al (2012), 66\% pasien DM tipe 2 dapat menderita retinopati diabetik setelah 10 tahun menderita diabetes. Penelitian Bin Bin He et al (2012)didapatkan 597 pasien menderita retinopati diabetik dari total sampel sebanyak 2009 pasien. Penelitian ini membagi durasi menderita diabetes melitus tipe 2 menjadi 3 golongan yaitu $<5$ tahun, $5-15$ tahun, $>15$ tahun. Dari penelitian tersebut didapatkan hasil pasien yang mengalami retinopati diabetik pada kategori $<5$ tahun sebesar $\pm 58 \%$, pada kategori 5-15 tahun $\pm 80 \%$, dan pada kategori $>15$ tahun $\pm 90 \%$ pasien. Hal ini menunjukkan bahwa semakin lama durasi pasien 
Sahreni S, Isramilda, Saputra AI : Hubungan Durasi Terdiagnosis Diabetes Melitus Tipe 2 dan Kadar Gula Darah Sewaktu Dengan Kejadian Retinopati Diabetik di Rumah Sakit Budi Kemuliaan Kota Batam Tahun 2017-2018

yang menderita Diabetes melitus tipe 2, maka semakin besar presentase untuk menderita Retinopati Diabetik.

\section{Perumusan Masalah}

Apakah ada hubungan antara Durasi waktu terdiagnosis Diabetes Melitus tipe 2 dan kadar Gula Darah dengan kejadian Retinopati dimana Glukosa merupakan karbohidrat terpenting yang kebanyakan diserap ke dalam aliran darah sebagai glukosa dan gula lain diubah menjadi glukosa di hati? Bagaimana Fungsi Glukosa Darah dengan penyakit DM?

\section{Tujuan Penelitian}

Tujuan penelitian ini adalah untuk mengetahui Hubungan antara Durasi waktu yang terdiagnosisi Diabetes Melitus 2 dan Kadar Gula Darah dengan kejadian Retinopati dan Fungsi Gula terhadap Penyakit DM.

\section{Manfaat Penelitian}

Adapun manfaat yang menjadi target temuan dalam penelitian ini adalah sebagai berikut:

1. Mendapatkan hasil hubungan antara durasi pasien penderita DM tipe 2 untuk menderita $\mathrm{RD}$

2. Sebagai referensi bagi para pasien bahwa ada DM tipe 2 merupakan Tipe Diabetes yang dapat menyebabkan keruskaan pada mikrovaskular dan retina

\section{METODE PENELITIAN \\ Desain Penelitian}

Melakukan uji Hiperglikemia kronik mengawali perubahan patologis pada retinopati diabetikum dan terjadi melalui beberapa jalur. Pertama, hiperglikemia memicu terbentuknya reactive oxygen intermediated (ROIs) dan advanced glycation endproducts (AGEs). ROIs dan AGEs merusak perisit dan endotel pembuluh darah serta merangsangpelepasan faktor vasoaktif seperti nitric oxide (NO), prostasiklin, insulin-like growth factor-1 (IGF-1), dan endotelin yang akan memperparah kerusakan pada kardiovaskular.

\section{Populasi dan Sampel}

Populasi penelitian ini adalah pasien Diabetes Melitus tipe 2 di Rumah Sakit Budi Kemuliaan Kota Batam. Besar sampel yang dipakai dalam penelitian ini terbagi menjadi 2 kelompok, tiap kelompok kasus dan kelompok kontrol berjumlah 33 orang. Jadi total sampel yang akan diteliti adalah berjumlah 66 orang.

\section{Tempat dan Waktu penelitian}

Penelitian ini dilaksanakan di Lokasi penelitian ini yaitu berada di Rumah Sakit Budi Kemuliaan Kota Batam Kepulauan Riau.

\section{Defenisi Operasional dan Indikator/Etika Kerja Islami}

Jenis penelitian ini merupakan penelitian analitik observasional dengan pendekatan studi case control,dengan menelaah hubungan antara efek (penyakit atau kondisi kesehatan) tertentu dengan faktor risiko tertentu (Dasar-dasar metodologi penelitian klinis, 2014). Pengumpulan data dalam penelitian ini dilakukan dengan menggunakan rekam medik. 
Sahreni S, Isramilda, Saputra AI : Hubungan Durasi Terdiagnosis Diabetes Melitus Tipe 2 dan Kadar Gula Darah Sewaktu Dengan Kejadian Retinopati Diabetik di Rumah Sakit Budi Kemuliaan Kota Batam Tahun 2017-2018

\section{Teknik Pengumpulan data dan Teknik Analisis Data}

Penelitian Bin Bin He et al (2012)didapatkan 597 pasien menderita retinopati diabetik dari total sampel sebanyak 2009 pasien. Penelitian ini membagi durasi menderita diabetes melitus tipe 2 menjadi 3 golongan yaitu $<5$ tahun, 5-15 tahun, $>15$ tahun. Dari penelitian tersebut didapatkan hasil pasien yang mengalami retinopati diabetik pada kategori $<5$ tahun sebesar $\pm 58 \%$, pada kategori 5-15 tahun $\pm 80 \%$, dan pada kategori $>15$ tahun $\pm 90 \%$ pasien. Hal ini menunjukkan bahwa semakin lama durasi pasien yang menderita Diabetes melitus tipe 2, maka semakin besar presentase untuk menderita Retinopati Diabetik.

\section{HASIL DAN PEMBAHASAN}

\section{A. Analisis Univariat}

1. Distribusi frekuensi Durasi Diabetes Melitus

Tabel 4.1. Distribusi frekuensi DM tipe 2

\begin{tabular}{ccc}
\hline $\begin{array}{c}\text { Durasi } \\
\text { diabetes } \\
\text { mellitus } \\
\text { tipe } 2\end{array}$ & $\begin{array}{c}\text { Frekuensi } \\
(\mathbf{f})\end{array}$ & $\begin{array}{c}\text { Persentase } \\
(\%)\end{array}$ \\
\hline$\leq 5$ tahun & 38 & 57,6 \\
$>5$ tahun & 28 & 42,4 \\
\hline Total & 66 & 100 \\
\hline
\end{tabular}

Dari tabel 4.1 diketahui penelitian ini dapat dijelaskan bahwa dari 66 orang yang diteliti sebanyak 38 orang (57,6\%) memiliki durasi Diabetes Melitus $\leq 5$ tahun, dan 28 orang $(42,4 \%)$ memiliki durasi Diabetes Melitus $>5$ tahun.

\section{Distribusi Frekuensi Kadar Gula Darah}

Tabel 4.2. Distribusi Frekuensi Kadar Gula Darah

\begin{tabular}{lll}
\hline Kadar & Frekuensi & $\begin{array}{l}\text { Persentase } \\
\text { Gula }\end{array}$ \\
Darah & & $(\%)$
\end{tabular}

Terkontrol

\begin{tabular}{lll} 
& 39 & 59,1 \\
$\begin{array}{l}\text { Tidak } \\
\text { terkontrol }\end{array}$ & 27 & 40,9 \\
\hline Total & 66 & 100 \\
\hline
\end{tabular}


Sahreni S, Isramilda, Saputra AI : Hubungan Durasi Terdiagnosis Diabetes Melitus Tipe 2 dan Kadar Gula Darah Sewaktu Dengan Kejadian Retinopati Diabetik di Rumah Sakit Budi Kemuliaan Kota Batam Tahun 2017-2018

Dari tabel 4.2 diketahui penelitian ini dapat dijelaskan bahwa dari 66 orang yang diteliti sebanyak 39 orang $(59,1 \%)$ memiliki kadar gula darah yang terkontrol, dan $27(40,9 \%)$ memiliki kadar gula darah terkontrol.

\section{Distribusi Frekuensi Kejadian Retinopati Diabetik}

Tabel 4.3. Distribusi Frekuensi kejadian Retinopati Diabetik

\begin{tabular}{lcc}
\hline $\begin{array}{l}\text { Kejadian } \\
\text { retinopati }\end{array}$ & $\begin{array}{l}\text { Frekuensi } \\
\text { (f) }\end{array}$ & $\begin{array}{l}\text { Persentase } \\
(\%)\end{array}$ \\
\hline $\begin{array}{l}\text { Tidak ada } \\
\text { retinopati }\end{array}$ & 33 & 50 \\
$\begin{array}{l}\text { Ada } \\
\text { retinopati }\end{array}$ & 33 & 50 \\
Total & 66 & 100 \\
\hline
\end{tabular}

Berdasarkan hasil Tabel 4.3 dapat dijelaskan bahwa dari 66 yang diteliti sebanyak 33 $(50 \%)$ orang tidak mengalami Retinopati, dan 33 (50\%) orang mengalami Retinopati.

\section{B. Analisis Bivariat}

\section{Hubungan Durasi Terdiagnosis Diabetes Melitus tipe 2 dengan kejadian Retinopati}

\begin{tabular}{|c|c|c|c|c|c|c|c|c|}
\hline \multirow{3}{*}{$\begin{array}{l}\text { Durasi } \\
\text { Terdiagnosis } \\
\text { Dm tipe } 2\end{array}$} & \multicolumn{4}{|c|}{ Kejadian Retinopati Diabetik } & \multirow{2}{*}{\multicolumn{2}{|c|}{ Total }} & \multirow{3}{*}{$\rho$ value } & \multirow{3}{*}{ Odd Ratio(OR) } \\
\hline & \multicolumn{2}{|c|}{ No RD } & \multicolumn{2}{|c|}{ RD } & & & & \\
\hline & $\mathrm{f}$ & $\%$ & $\mathrm{f}$ & $\%$ & $\mathrm{f}$ & $\%$ & & \\
\hline$\leq 5$ tahun & 26 & 68,4 & 12 & 31,6 & 38 & 100 & 0,000 & 6,500 \\
\hline$>5$ tahun & 7 & 25,0 & 21 & 75,0 & 28 & 100 & & \\
\hline Jumlah & 33 & & 33 & & 66 & & & \\
\hline
\end{tabular}

Dari tabel 4.4 dari 66 responden yang diteliti dapat diketahui bahwa pasien yang memiliki durasi terdiagnosis Diabetes Melitus tipe $2 \leq 5$ tahun dengan tidak Retinopati Diabetik adalah sebesar $26(68,4 \%)$ orang, yang memiliki durasi $\leq 5$ tahun dengan Retinopati sebesar 12 $(13,6 \%)$ orang, dan pasien yang memiliki durasi $>5$ tahun dengan tidak

Retinopati diabetik sebesar $7(25,0 \%)$ orang, sedangkan pasien yang memiliki durasi terdiagnosis Diabetes melitus tipe $2>5$ tahun dengan Retinopati sebesar $21(75,0 \%)$ orang. Dari analisis data didapatkan nilai $p=0,000$. Angka tersebut menunjukkan angka signifikan karena nilai $\mathrm{p}$ lebih kecil dari taraf signifikasi $(\alpha)=0,05$. Dengan demikian dapat disimpulkanbahwa Ho ditolak dan Ha diterima atau terdapat hubungan bermakna antara durasi terdiagnosis diabetes mellitus tipe 2 dengan kejadian Retinopati diabetik. Hasil Uji Risk Estimate menunjukkan nilai Odds Ratio $(O R)=6,500$. OR $>1$ Yang artinya, pasien 
Sahreni S, Isramilda, Saputra AI : Hubungan Durasi Terdiagnosis Diabetes Melitus Tipe 2 dan Kadar Gula Darah Sewaktu Dengan Kejadian Retinopati Diabetik di Rumah Sakit Budi Kemuliaan Kota Batam Tahun 2017-2018

dengan durasi Diabetes Melitus $\leq 5$ tahun yang mengalami Retinopati Diabetik mempunyai resiko 6,500 lebih tinggi daripada pasien $>5$ tahun.

\section{KESIMPULAN}

\section{A. Kesimpulan}

a. Berdasarkan hasil dari pencatatan rekam medis, didapatkan lebih dari setengah pasien yang terdiagnosis diabetes melitus tipe 2 lebih dari 5 tahun mengalami retinopati diabetik $(75,0 \%)$.

b. Berdasarkan hasil dari pencatatan rekan medis, didapatkan sebagian besar pasien dengan kadar gula darah terkontrol mengalami retinopati diabetik $(66,7 \%)$.

c. Berdasarkan hasil dari pencatatan rekam medis, didapatkan 66 yang diteliti sebanyak 33 orang $(50 \%)$ tidak ada retinopati, dan 33 orang (50\%) ada retinopati

d. Terdapat hubungan bermakna dan kekuatan yang cukup antara durasi terdiagnosis diabetes mellitus tipe 2 dengan kejadian retinopati diabetik dengan nilai $\mathrm{p}=0,000$ ( $\mathrm{p}$ $\leq 0,05)$

e. Terdapat hubungan bermakna dan kekuatan yang cukup antara kadar gula darah dengan kejadian retinopati diabetik dengan nilai $p=0,024(p \leq 0,05)$.

\section{DAFTAR PUSTAKA}

Aillo L., Cahill M.M.J. (2001). Systemic Consideration in the Management of Diabetic retinophathy; American Journal of Ophthalmology. 132:760-776

American Diabetes Association (2010). Diagnosis and Clasification of Diabetes, Diabetes Care 1 Januari 2014 vol : 27

Anugrah J. Hubungan diabetes melitus dan retinopati di RSUD DR Soedorso Pontianak periode Januari- Desember (2010). FK Universitas Tanjungpura; 2013

Bin-Bin He, LiWei, Yun JG, Jun FH, Ming L, Yu-Xiang L, et al. Clinical Study: Factors Associated with Diabetic Retinopathy in Chinese Patients with Type 2 Diabetes Mellitus. Hindawi Publishing Corporation International Journal of Endocrinology Volume 2012; 1-8

Cheung et al. (2010). Diabeticretinopathy. Lancet. 376(9735): 124-136

Depkes R.I., (2008). Profil Kesehatan Indonesia. Jakarta

Diana Susanto. (2009). Oftalmologi Umum Vaughan \&Asbury, Ed. 17. Jakarta: Penerbit Buku Kedokteran EGC

IDF, (2011), One Adult In Ten Will Have Diabetes by 2003.

Jones CD,dkk. (2012). Incidence and progression of diabetic retinopathy during 17 years of a population-based screening program in England. Diabetes Care. 35(3): 592-596.

Kemenkes RI. Profil Kesehatan Indonesia tahun 2014. Jakarta : Kemenkes RI; 2015

Notoatmodjo. (2010). Metodologi Penelitian Kesehatan. Jakarta : PT. Rineka Cipta

Pandelaki, K. (2009). Retinopati Diabetik. Jakarta: Interna Publishing

PERKENI. (2011). Konsensus pengelolaan diabetes melitus tipe 2 di indonesia 2011. Semarang: PB PERKENI

Ranakusuma, A.B., (2007). Penyakit Kencing Manis Diabetes Mellitus. UI-Press. Jakarta.

Sitompul, Ratna. (2011). Retinopati Diabetik. J Indon Med Assoc, Volum: 61, Nomor: 8, Agustus 2011

Sugiyono. (2014). Metode Penelitian Pendidikan Pendekatan Kuantitatif, Kualitatif Dan R\&D. Bandung: Alfabeta. 
Sahreni S, Isramilda, Saputra AI : Hubungan Durasi Terdiagnosis Diabetes Melitus Tipe 2 dan Kadar Gula Darah Sewaktu Dengan Kejadian Retinopati Diabetik di Rumah Sakit Budi Kemuliaan Kota Batam Tahun 2017-2018

Victor, dkk., (2008), Retinopati Diabetik Penyebab Kebutaan Utama Penderita Diabetes, Departemen Mata FKUI/RSCM, Jakarta

Wei Pan dkk. (2011). Worldwide prevalence and risk factors for myopia. Opthalmic \& Physiological Optics

Weiss J. (2008). Emulsion Processing : Homogenization. Emulsion Workshop. Germany : Department of Food Science and Biotechnology, Universitt of Hohenheim

Yau JWY,dkk. (2012). Global prevalence and major risk factors of diabetic retinopathy. Diabetes Care. 35: 556-64. 